\title{
Epilepsia e Direção de Veículos
}

Regina Sivia Alves de Lima*, Mauro Muszkat** \& Carlos José Reis de Campos***

\section{RESUMO}

Análise e discussão dos aspectos médico-sociais relacionados à licença para direção de veículos em pacientes epilépticos.

\section{UNITERMOS}

Epilepsia; Direçāo de veículos.

\section{ASPECTOS GERAIS}

Dirigir veículos na sociedade moderna significa para muitos não apenas status e prazer, mas fundamentalmente um instrumento de independência social, profissional e econômica (Krumholz et al., 1991). Para os pacientes epilépticos, sujeitos à várias restriçōes relacionadas à imprevisibilidade das crises e ao estigma, a impossibilidade legal de dirigir veículos automotores, além de significar mais uma limitação, pode ser vivenciada como uma grande desvantagem para sua ascensão social, acentuando sentimentos de incapacidade, inadequação e baixa auto-estima (Parsonage, 1990; Krumholz et al., 1991).

A licença para pacientes epilépticos dirigirem veículos envolve aspectos éticos polêmicos, que vão desde a aceitação ou não pelo paciente e familiares das limitações impostas pela epilepsia até a avaliação de como este indivíduo reage enquanto cidadão frente aos seus direitos e deveres que se iniciam no instinto de auto-preservação e findam no cuidado para com o próximo. Outros pontos controversos relacionam-se à este tema, como por exemplo qual o tempo ideal que os pacientes epilépticos deverão estar sem crises para a liberação da licença; quais os tipos de crises epilépticas que representam maior ou menor risco diante do ato de dirigit veículos; qual o papel do eletrencefalograma como exame subsidiário para a autorização da licença para pacientes epilépticos; qual a responsabilidade médico-legal nos acidentes provocados por pacientes epilépticos; qual a relevância da preservação do sigilo médico e do vínculo médico-paciente diante da possibilidade real de expor pessoas a acidentes. Abordaremos neste artigo alguns aspectos das complexas implicaçōes médico-sociais relacionados à licença para pacientes epilépticos dirigirem veículos automotores.

\section{REGULAMENTAÇÃO LEGAL - A EXPERIÊNCIA INTERNACIONAL}

Embora possamos acreditar ser alta a probabilidade de pacientes com epilepsia provocarem acidentes de trânsito, o risco total para acidente de tráfego em indivíduos epilépticos, particularmente os fatais, é bem inferior aos observados em outras circunstâncias, como por exemplo com pessoas alcoolizadas (Krumholz, et al., 1991).

Os primeiros acidentes de tráfego atribuídos à epilepsia foram relatados em 1906 por Franz Thalwitzer (Apud Krumholz, et al., 1991). Quando se tornou obrigatória a 
licença para direção de veículos, devido a preocupação com a segurança, essa autorização passou a ser recusada para os pacientes epilépticos (Van der Lugt, 1975).

A partir de 1940, com o avanço da eletrencefalografia e do tratamento da epilepsia com drogas eficazes, foi observado que muitos epilépticos tinham suas crises controladas e, portanto, poderiam estar aptos a dirigir veículos com segurança. Uma iniciativa pioneira mais liberal surgiu no estado de Wisconsin (EUA) em 1949, cuja legislação passou a permitir que pacientes epilépticos dirigissem veículos temporariamente e sob rigoroso controle (Helbach \& Point, 1991).

Embora as leis sejam diferentes em vários países desenvolvidos, observa-se comumente algumas restrições em conceder aos pacientes epilépticos licença para dirigir, como uma forma de proteger os cidadãos dos acidentes de trânsito provocados por um paciente durante uma possível crise epiléptica. Tais restrições relacionam-se, principalmente, à necessária ausência de crises epilépticas por um período de tempo prolongado e a ausência de anormalidades eletrencefalográficas em EEG periódicos (Laidlaw \& Laidlaw, 1982, Parsonage, 1990). Desde 1982, a legislação vigente no Reino Unido tem servido de paradigma para a regulamentação em vários países em desenvolvimento (Parsonage, 1990). Tal regulamentação estabelece que pacientes epilépticos podem obter licença para dirigir veículos automotores desde que satisfaçam as seguintes condições (Laidlaw \& Laidlaw 1982):

1 - Período livre de qualquer tipo de crises epilépticas nos 2 anos que antecedem a data de liberação da licença.

2 - Período livre de crises equivalentes a 3 anos em pacientes com história de crises exclusivamente durante o sono.

3 - Uma vez preeenchido os critérios 1 e 2, a licença será concedida somente para carteira de amador, não podendo, de modo algum, o paciente epiléptico obter em licença para dirigir veículos de carga ou transporte público de passageiros.

Ressalta-se que no caso de ocorrência de crise epiléptica após obtenção da licença, esta será suspensa por 1 ano e se houver recorrência um novo período de 2 anos sem crises é exigido na tentativa de readquirí-la (Laidlaw \& Laidlaw, 1982; Spudis et al., 1986).

Nos Estados Unidos o tempo livre de crises necessário para obtenção de licença varia de estado a estado, indo de 3 meses a 2 anos (Parsonage, 1990). Na Bélgica, Dinamarca, Finlândia, França, Noruega, Suécia, Suiça, Alemanha, Canadá, Israel o tempo livre de crises varia de 1 a 2 anos (Parsonage, 1990; Krumholz et al., 1991). Na Áustria, Itália, Grécia, Espanha, Índia, Paquistão e Japão é vedado aos pacientes epilépticos a obtenção de qualquer tipo de licença para a direção de veículos, embora atualmente alguns destes países estejam revendo suas posições (Parsonage, 1990; Krumholz et al., 1991).

No Brasil não há regulamentação específica para a habilitação de motoristas epilépticos. O que existe em vigor é a resolução 504/76 do Conselho Nacional de Trânsito, artigo 39, parágrafo 4, item 2, que diz: "Deverão ser considerados inaptos definitivamente os candidatos que sejam portadores de lesão cardiovascular ou cerebral ou ainda outras lesōes das quais possam advir perigo para a segurança do trânsito". Esta resolução mostra-se bastante ultrapassada ao considerar os pacientes epilépticos como portadores de "lesão cerebral" (Marques-Assis \& Luzio, 1985), haja vista que as epilepsias constituem uma síndrome que envolve condiçōes clínicas bastante heterogêneas em relação ao prognóstico, a resposta à medicação e a presença ou não de alterações estruturais do cérebro, devendo-se lembrar que, nas epilepsias primárias e criptogênicas não há qualquer evidência de lesảo cerebral estrutural.

Recentemente, com base em uma recomendação da Associação Brasileira de Medicina de Tráfego, o DETRAN de São Paulo informa que poderá ser fornecida carteira de amador para pacientes epilépticos desde que sejam respeitados os seguintes critérios (ABMT, 1991):

1. Tempo mínimo sem crises de 2 anos.

2. No casos de crises em sono, tempo mínimo sem crises de 3 anos.

3. Recomenda-se não dirigir veículos à noite, nem em estradas de pouco movimento.

4. Recomenda-se não dirigir veículos à época de retirada ou substituição de drogas antiepilépticas.

5. A responsabilidade de informação é do paciente, cabendo ao médico orientação.

No entanto, como vimos anteriormente, estas recomendações não encontram respaldo na legislação vigente. É necessário ressaltar que no Brasil os pacientes epilépticos que dirigem veículos não estão sujeitos a uma supervisão periódica pelos órgāos de trânsito e perícia médica, não havendo integração entre os locais de atendimento médico-neurológico e os orgãos oficiais de regulamentação. Neste contexto, como saber qual paciente epiléptico está sem crises, tomando regularmente suas medicações ou em período de substituição de drogas antiepilépticas? Assim, muitas vezes, a cassação da licença só é realizada após a ocorrência de um acidente real, quando é inferida uma relação causal entre a crise e o acidente. Podemos constatar, então, que em nosso país não existe efetivamente uma abordagem de caráter preventivo com relação a epilepsia e os acidentes de trânsito.

\section{ASPECTOS PECULIARES}

Embora exista legislação mais ou menos definida na maioria dos países desenvolvidos quanto a licença para epilépticos dirigirem veículos automotores, há muita controvérsia entre os especialistas. Tal controvérsia diz respeito a situaçōes peculiares não previstas na legislação. Isto inclui: casos de crises epilépticas únicas ou crises epilépticas reflexas (desencadeadas por sons como buzinas, ou então luz como faróis ou padrões alternos de estímulos luminosos, como ocorre com cercas em estradas), pacientes com crises somente durante o sono, com crises sempre de início parcial (com "avisos" ou "aura"), com crises fortuitas desencadeadas por distúrbios metabólicos, intoxicação por uso indevido ou supressão de medicamentos 
antiepilépticos ou então, no caso de tratamento antiepiléptico preventivo para as infecçōes graves do SNC e nos pacientes submetidos a craniotomia, ou com traumatismos crânio-encefálico grave e nos casos de distúrbios de consciência de etiologia incerta.

Uma vez que nessas situações a legislação não é clara, julgamos ser de fundamental importância efetuar avaliação $e$ supervisão mais criteriosa e periódica destes casos, com assessoria de profissionais com conhecimento específico e que disponham dos exames subsidiários necessários para um estudo neurofisiológico mais detalhado. Embora o EEG realizado interictalmente possa não trazer subsídios para o diagnóstico, especialmente quando resulta normal, a presença de anormalidades persistentes, como descargas por complexos ponta-onda, sugere a necessidade de um acompanhamento mais rigoroso e periódico, mesmo em se tratando de crise epiléptica única. Também nos casos de distúrbios paroxísticos de consciência de causa não definida, consideramos que só deve ser liberada a licença para direção de veículos após uma investigação apropriada, que muitas vezes pode implicar em monitorização cardíaca e eletrencefalográfica prolongada do tipo Holter, especialmente quando se tratar de motoristas profissionais.

\section{NOTIFICAÇÃO E RESPONSABILIDADE MÉDICO-LEGAL}

No Reino Unido, todos os indivíduos que tiveram uma única crise epiléptica ou que desenvolveram epilepsia com crises recorrentes são obrigados a notificá-las ao Departamento de Trânsito. Além disso, os serviços de neurologia e neurocirurgia são orientados a comunicar ao tribunal os casos de acidentes envolvendo pacientes epilépticos na direção de veículos (Kuhl et al., 1967; Parsonage, 1990). Em alguns estados americanos (EUA) a responsabilidade da informação às autoridades é do médico que acompanha o tratamento dos pacientes epilépticos. Nesta situação, a não notificação aos órgãos de trânsito, tem gerado processos judiciais contra médicos neurologistas, pelas partes que se julgam prejudicadas por acidentes causados por pacientes epilépticos dirigindo veículos (Helbach \& Point 1991; King et al., 1992; Salinsky et al., 1992).

Consideramos que não cabe aos médicos delatar seus pacientes às autoridades, uma vez que a notificação compulsória implica habitualmente em quebra de sigilo médico e deterioração da relação médico-paciente, devendo ser rigorosamente analisados os casos que coloquem em risco a saúde pública (Parsonage, 1990). Medidas coercitivas e autoritárias podem ser facilmente burladas pelo paciente, que pode omitir suas crises diante da autoridade médica institucional. É comum pacientes epilépticos não mencionarem suas crises ao solicitarem licença para dirigir. Maxwell \& Leyshon (1971) observaram que 90\% dos pacientes epilépticos omitem seu diagnóstico ao solicitarem licença. Van der Lugt (1975) observou que 1968 jovens solicitaram dispensa do serviço militar da Holanda, alegando serem epilépticos. Cinco anos após, $699(35 \%)$ deles haviam solicitado licença para dirigir e somente $65(9 \%)$ admitiram serem portadores de epilepsias. Salinsky et al. (1992) observaram que, mesmo após a cassação da licença, $17 \%$ dos pacientes epilépticos com crises não controladas continuam a dirigir automóveis clandestinamente. Krumholz et al. (1991) acreditam que medidas restritivas são contraproducentes e desestimulam a obediência dos indivíduos à regulamentação institucional. Isto pode explicar o fato de que em países com leis de trânsito mais restritivas não há melhor prevenção de acidentes relacionados às crises epilépticas (Gastaut \& Zifkin, 1987).

\section{CONSIDERAÇÕES FINAIS}

A análise pericial de pacientes epilépticos deve ser extremamente criteriosa e na avaliação da concessão de licença a estes pacientes, os serviços periciais devem estar assessorados por profissionais com conhecimento técnico atualizado sobre os vários aspectos das epilepsias, para que possam proporcionar uma análise minuciosa de cada caso. No entanto, consideramos que não cabe ao médico neurologista emitir laudos periciais para seus pacientes podendo, entretanto, uma vez solicitado por médicos do serviço de trânsito, auxiliar os órgãos competentes, fornecendo informaçōes atualizadas sobre o estado clínico e os exames subsidiários realizados em seus pacientes. Compete ao médico perito aplicar as regras de regulamentação da licença de maneira flexível, solicitando aos médicos especialistas um parecer confidencial toda vez que julgarem necessário. Acreditamos ser incumbência dos médicos assistentes orientar técnica e humanisticamente seus pacientes a assumir uma postura responsável e ética diante do problema.

Os profissionais da saúde poderão colaborar também no aspecto humano do tratamento dos pacientes epilépticos e seus familiares, uma vez que estes enfrentam várias dificuldades para reestruturar-se frente ao preconceito, a aceitação dos limites impostos pela epilepsia, de maneira geral, e mais especificamente frente a restrição da licença para dirigir veículos. Estas dificuldades geralmente são difíceis de serem assimiladas, principalmente por adolescentes e motoristas profissionais que enfrentam o problema. A maioria dos adolescentes anseiam por obter sua carta de motorista, pois esta representa para eles independência, liberdade, virilidade e acesso a vida adulta. Outra característica desta faixa etária é a dificuldade em condicionar-se às regras que norteiam os diferentes sistemas sociais nos quais estão inseridos. Estes fatores aliam-se muitas vezes a tendência dos pais em cederem as pressões dos filhos e, portanto, não delimitarem com segurança o melhor período de obtenção da carta de habilitação.

Os motoristas profissionais que tornam-se epilépticos e, por esta razão perdem sua carteira de habilitação, enfrentam dificuldades que têm repercussões econômicas e sociais mais graves, principalmente quando este indivíduo é arrimo de família. Estes profissionais, por vezes especializados em direção e trans- 
porte de veículos de carga ou de passageiros, geralmente dispõe de um bom potencial profissional, que poderia ser utilizado por serviços de reabilitação, favorecendo a reintegração destes indivíduos ao mercado de trabalho. A abordagem familiar neste caso se faz necessária no sentido de compreender a dinâmica da familia frente a epilepsia, procurando facilitar a reorganização do sistema familiar frente ao problema e potencializar os recursos pessoais destes pacientes para enfrentarem as dificuldades sociais com as quais poderão se deparar.

As mudanças de atitude dificilmente são efetivadas através de imposições e restrições, mas poderão ser facilitadas diante de um trabalho técnico respaldado por uma vinculação positiva, onde prevaleça um clima de compreensão e aceitação das dificuldades sociais e emocionais vivenciadas pelos indivíduos e seus familiares.

O preconceito e o estigma associados à epilepsia são outros fatores que podem prejudicar tanto o acesso a obtenção de licença, mesmo em pacientes sem crises há vários anos, como também dificultar a aquisição dos sentimentos de aceitação destes pacientes frente a privação de dirigir veículos.

Auxiliar os pacientes epilépticos a agirem de maneira responsável e consciente é dever de todo profissional de saúde e pode significar um trabalho árduo, uma vez que nossa sociedade não se encontra suficientemente organizada no sentido de oferecer opçōes profissionais e de reabilitação que correspondam às reais necessidades de seus cidadãos.

A direção de veículos tem grande importância em nossa sociedade e sua restrição pode representar sérias dificuldades do ponto de vista econômico e social àqueles que são impedidos de usufruir deste direito. No caso específico dos pacientes epilépticos, consideramos necessária a união de peritos, especialistas e profissionais da saúde no sentido de buscar um equilibrio adequado entre o bem estar público e o dos pacientes epilépticos. Para tal, consideramos necessária uma revisão sistemática da legislação em vigor, adequando-as à nossa realidade de acordo com os conhecimentos atuais da epileptologia, incluindo uma maior comunicação entre os órgãos de medicina do tráfego e entidades relacionadas com a questão, como por exemplo a Liga Brasileira de Epilepsia.

(Apoio Financeiro: CNPq $\in$ FINEP)

\section{SUMMARY}

Problems related to driver's licence for epileptic patients are analysed and commented.

\section{KEY WORDS}

Epilepsy. Driving.

\section{Bibliografia}

1 ASSOCIAÇÃO BRASILEIRA DE MEDICINA DE TRÁFEGO (ABMT), Boletim Informativo, DETRAN São Paulo, 10/10/1991.

2 ANNEGERS, J.F.; HAUSER, W.A.; ELVEBACK, L.R. - Remission of seizures and relapse in patients with epilepsy. Epilepsia, 20:729-37, 1979.

3 GASTAUT, H; ZIFKIN, B.G. - The risk of automobile accidents with seizures occurring while driving: relation to seizure type. Neurology, 37:1613-16, 1987.

$4 \mathrm{HELBACH}, \mathrm{D}$.; POINT, S. - A legislative view of driving and legal restriction. Wis. Med. J., 90 (3) :119-20, 1991.

5 KING, D.; BENBOW, S.J.; BARRETT, A.- The law and medical fitness to drive - a study of doctors knowledge. Post Grad. Med. J., 68:624-28, 1992.

6 KUHL, V.; KIORBOE, E.; LUND, M. - The prognosis of epilepsy with special reference to traffic security. Epilepsia, 8:195-209, 1967.

7 KRUMHOLZ, A.; FISHER, R.S.; LESSE, R.P., HAUSER, A. - Driving and Epilepsy. JAMA, 6 (265): 622-26, 1991.

8 LAIDLAW, J.S.; LAIDLAW, M.V. - People with epilepsy: living with epilepsy. In: Laidlaw, J.S. \& Richens, A. (Ed.) A textbook of epilepsy. 2 ed., Edinburg, Churchil Livingstone, 1982, p. 543-4.

9 MARQUES-ASSIS, L.; LUZIO, J. - Epilepsia e licença para dirigir veículos. Rev. Paul. Med., 103 (2): 99-101, 1985.

10 MAXWELL, R.D.H.; LEYSHON, G.E. - Epilepsy and Driving. Br. Med. J., 3:12-15,1971.

11 PARSONAGE, M. - Driver's Licenses. In: Comprehensive Epileptology, Dam, M. \& Lennart, G. (Ed.), Raven Press, New York, 1990, p. 743-52.

12 SALINSKY, M.C.; WEGENER, K.; SINNEMA, F. - Epilepsy driving laws and patient disclosure to physicians. Epilepsia, 33(3): 469-72, 1992.

13 SPUDIS, E.V.; PENRY, J.K.; GIBSON, P.- Driving impairment caused by episodic brain dysfunction. Arch. Neurol., 43:558-64, 1986.

14 VAN DER LUGT, P.J.M. - Traffic accidents caused by epilepsy. Epilepsia, 167:747-51, 1975. 